\title{
Prevention of experimental autoimmune encephalomyelitis in Lewis rats by a novel fungal source of $\boldsymbol{\gamma}$-linolenic acid
}

\author{
BY L. S. HARBIGE', N. YEATMAN², S. AMOR' AND M. A. CRAWFORD \\ ${ }^{1}$ Immunology Department, United Medical and Dental Schools of Guy's and St Thomas' Hospitals, \\ The Rayne Institute, St Thomas' Hospital, London SE1 7EH \\ ${ }^{2}$ Immunology Department, The Royal London Hospital Medical College, London E1 $2 A B$ \\ ${ }^{3}$ Institute of Human Nutrition and Brain Chemistry, Queen Elizabeth Hospital for Children, \\ Hayward Building (3rd Floor), Hackney Road, London E2 8PS
}

(Received 15 September 1994 - Accepted 28 February 1995)

\begin{abstract}
The effects of oral administration of linoleic- and $\gamma$-linolenic-acid-rich oils on the clinical and histopathological manifestations of experimental autoimmune encephalomyelitis (EAE) were investigated in Lewis rats $7 \mathrm{~d}$ post-inoculation. $\gamma$-Linolenic-acid-rich fungal (Mucor javanicus) oil at $500 \mathrm{mg} / \mathrm{kg}$ body weight abrogated clinical and histological signs of EAE although at doses of 200 and $1000 \mathrm{mg} / \mathrm{kg}$ body weight it was only effective in delaying the onset of clinical disease. Linoleic-acid-rich safflower-seed (Carthamus tinctorius) oil at 500,750 and $1000 \mathrm{mg} / \mathrm{kg}$ body weight decreased the severity of clinical EAE disease in a dose-dependent manner. The effects in healthy animals of orally administered $\gamma$-linolenic-acid-rich fungal oil ( $500 \mathrm{mg} / \mathrm{kg}$ body weight) and linoleic-acid-rich safflower-seed oil $(1000 \mathrm{mg} / \mathrm{kg}$ body weight) on splenic lymphocyte proliferative responses to the $T$-cell mitogen concanavalin-A (Con A), membrane fatty acid composition and lymphocyte sub-sets were also studied. Both treatments enhanced the $T$-cell proliferative response to Con $\mathbf{A}$. There was no significant effect on the proportion of splenic $\mathrm{CD8}^{+}$or $\mathrm{CD4}^{+}$lymphocytes. Compositional studies on splenic phosphoglyceride fatty acids of oil-treated animals suggest the above responses were associated with increases in spleen dihomo- $\gamma$-linolenic and arachidonic acids.
\end{abstract}

Linoleic acid: $\boldsymbol{\gamma}$-Linolenic acid: Experimental autoimmune encephalomyelitis

Experimental autoimmune encephalomyelitis (EAE) is an autoimmune inflammatory and demyelinating disease of the central nervous system (CNS) inducible in rodents and other mammalian species by active or adoptive sensitization to CNS constituents (Paterson, 1980; Lassmann, 1983). It has been used extensively as an animal model of the human demyelinating condition multiple sclerosis, the pathogenesis of which is probably immunemediated (Lassmann, 1983; Alvord et al. 1984; Bernard \& Kerlere de Rorbo, 1992; ffrenchConstant, 1994). Following immunization of rodents with neuroantigen(s) in Freund's complete adjuvant, there is proliferation of CNS-reactive T-lymphocytes in regional lymphoid tissues, migration of blood-borne $\mathrm{CD4}^{+} \mathrm{T}$-lymphocytes across the blood-brain barrier, and recruitment of inflammatory mononuclear leucocytes into the CNS (Paterson, 1980; Fallis et al. 1987; Hayosh et al. 1989; Cross et al. 1991). Meade et al. (1978) and Hughes et al. (1980) found that linoleic acid could partially suppress guinea-pig EAE when given continuously or $7 \mathrm{~d}$ post-inoculation. Furthermore, Mertin \& Stackpoole (1978, 1979 ) and Mertin (1981) found that a high-linoleic-acid and low- $\gamma$-linolenic-acid-rich oil given $7 \mathrm{~d}$ post-inoculation partially suppressed EAE in the rat. Mertin \& Stackpoole (1978, 1979) found that this partial suppression in the rat could be abolished by treatment with indomethacin and that splenectomy could abrogate the suppressive effect. The conclusions 
drawn from this work were that the suppressive effects of $n-6$ essential fatty acids on EAE are derived from prostaglandins produced in the spleen. Moreover, patients with the demyelinating condition multiple sclerosis show abnormalities in the metabolism of $n-6$ essential fatty acids (Baker et al. 1964; Sanders et al. 1968; Tsang et al. 1976; Neu, 1983; Cherayil, 1984; Harbige et al. 1986; Fisher et al. 1987; Navarro \& Segura, 1989), and oral treatment with linoleic-acid-rich oil has been found to have a beneficial influence on the disease course (Dworkin et al. 1984).

The present study was undertaken (1) to compare the effects of linoleic-acid-and $\gamma$ linolenic-acid-rich oils on clinical and histopathological criteria of EAE in Lewis rats, (2) to assess the effects of linoleic- and $\gamma$-linolenic-acid-rich oils on splenic T-lymphoproliferative responses and lymphocyte sub-sets, and (3) to determine the metabolic effects of the oil-derived linoleic and $\gamma$-linolenic acids in spleen tissue.

\section{EXPERIMENTAL PROCEDURES}

\section{Induction of experimental autoimmune encephalomyelitis}

Xenogenic CNS (brain stem and spinal cord) from adult Hartley guinea pigs was mixed with Hank's balanced salt solution $(1: 1, \mathrm{w} / \mathrm{v})$ and emulsified (Silverson Machines Ltd., Chesham, Bucks.) together with an equal amount (v/v) of Freund's complete adjuvant (CFA) obtained from Difco (Detroit, MI, USA). Of this CFA-CNS emulsion, $0.2 \mathrm{ml}$ was injected under light diethyl ether anaesthesia into the ventral surface of each paw of 8-9week-old female Lewis rats obtained from Charing Cross Hospital Medical School, Comparative Biology Unit, London.

\section{Treatment with essential-fatty-acid-rich oils}

Essential-fatty-acid-rich oils were administered orally by intragastric tube starting on day 7 post-inoculation and continuing until day 21, using Jaque's type Nelation catheters size 8 (Portex Ltd., Portland, Hants). Two essential-fatty-acid-rich oils were used; these were linoleic-acid-rich $(660 \mathrm{~g}$ linoleic acid $/ \mathrm{kg}$ ) safflower-seed (Carthamus tinctorius) oil and $\gamma$ linolenic (190 $\mathrm{g} \gamma$-linolenic acid $/ \mathrm{kg}$ ) acid-rich fungal (Mucor javanicus) oil. The full compositions of the basal diet and oils are given in Tables 1 and 2 respectively. The fatty acid oil sources were tested at an initial dose of $500 \mathrm{mg} / \mathrm{kg}$ body weight on Lewis rat EAE. Dose-response studies were also carried out with safflower-seed oil at 500,750 and $1000 \mathrm{mg}$ linoleic acid $/ \mathrm{kg}$ body weight and with fungal oil at 200,500 and $1000 \mathrm{mg} \gamma$-linolenic $\mathrm{acid} / \mathrm{kg}$ body weight on EAE. Saline treatment of sensitized animals was carried out to control for the effects of oil and dosing procedure.

\section{Assessment of experimental autoimmune encephalomyelitis}

Clinical scoring of EAE was as follows: 0, no clinical signs; 1, limp tail (loss of tail tonicity); 2 , weakness of hindlimbs (one or both); 3 , partial hindlimb paralysis; 4, complete paralysis of hindlimbs; 5 , as 4 plus incontinence and/or front limb paralysis; 6 , death. At least two animals per experimental group were injected with CFA emulsion only to control for localized footpad swelling, and the subsequent effect on the gait of the animals.

\section{Histology}

At $21 \mathrm{~d}$ post-inoculation the spinal cord and hindbrains were routinely processed for histology. Paraffin-wax-embedded tissues were sectioned with a rotary microtome (Leitz, Wetzlar, Germany) at $5 \mu \mathrm{m}$, mounted on glass slides and stained with haematoxylin and eosin. Histological assessments of EAE were graded by number of perivascular 
Table 1. Composition of the basal diet*

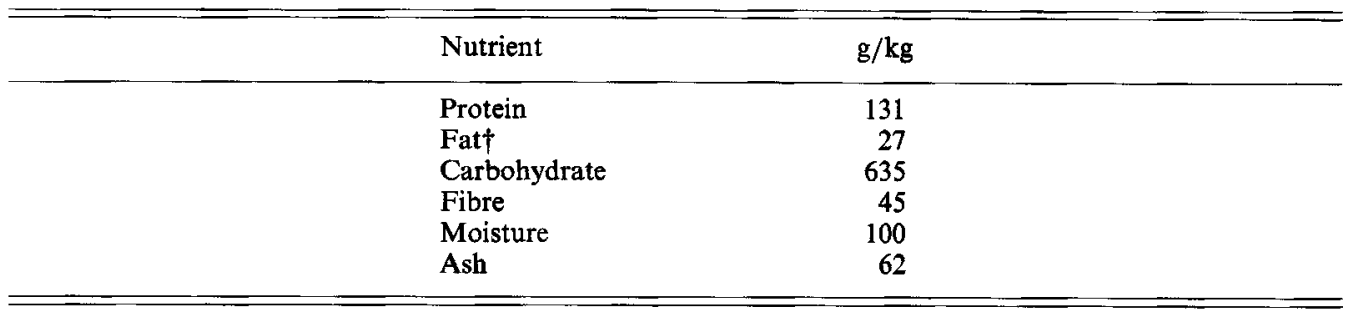

* The diet included the following vitamins and minerals (per $\mathrm{kg} \mathrm{diet}$ ): $\mathrm{DL}-\alpha$-tocopherol $70 \mathrm{mg}$, retinol $1983 \mu \mathrm{g}$, ascorbic acid $11 \mathrm{mg}, \mathrm{Cu} 11 \mathrm{mg}, \mathrm{Zn} 18 \mathrm{mg}, \mathrm{Se} 192 \mu \mathrm{g}$.

$\dagger$ Contained the following fatty acids $(\mathrm{g} / \mathrm{kg}$ diet): myristoleic 0.2 , palmitoleic 0.8 , oleic $7 \cdot 7$, linoleic 6.8 , $\alpha$-linolenic $0 \cdot 6$, arachidonic $1 \cdot 3$, lauric $0 \cdot 2$, myristic $1 \cdot 4$, palmitic $3 \cdot 2$, stearic $0 \cdot 4$.

Table 2. Fatty acid compositions of the oils ( $\mathrm{g} / 100 \mathrm{~g}$ total fatty acids measured)

\begin{tabular}{llcc}
\hline Fatty acid & & $\begin{array}{c}\text { Safflower } \\
\text { (Carthamus }\end{array}$ & $\begin{array}{c}\text { Fungal } \\
\text { (Mucor javanicus) oil } \dagger\end{array}$ \\
\hline Myristic & $14: 0$ & - & $3 \cdot 5$ \\
Palmitic & $16: 0$ & $9 \cdot 8$ & $13 \cdot 7$ \\
Stearic & $18: 0$ & $2 \cdot 8$ & $3 \cdot 4$ \\
Arachidic & $20: 0$ & - & $2 \cdot 3$ \\
Palmitoleic & $16: 1$ & - & - \\
Oleic & $18: 1$ & $17 \cdot 0$ & $34 \cdot 7$ \\
Gadoleic & $20: 1$ & - & - \\
Linoleic & $18: 2 n-6$ & $66 \cdot 0$ & $17 \cdot 5$ \\
$\gamma$-Linolenic & $18: 3 n-6$ & - & $19 \cdot 3$ \\
\hline
\end{tabular}

* Prewetts, West Byfleet, Surrey.

$\dagger$ John E. Sturge Ltd, Selby, Yorks.

mononuclear infiltrated sites following the protocol: - , no lesions; + , up to four or five lesions on the entire section; ++ , a few lesions in each of several different low-power fields; +++ , lesions in many different fields; ++++ , many lesions in all or almost all fields.

Animals and treatments for ex vivo investigations

Healthy female Lewis rats (8-9 weeks old) were used in these studies. Spleens were aseptically removed from control untreated animals and animals given oral safflower-seed oil at $1000 \mathrm{mg}$ linoleic acid $/ \mathrm{kg}$ body weight or fungal oil at $500 \mathrm{mg} \gamma$-linolenic acid $/ \mathrm{kg}$ body weight daily for 4 or $12 \mathrm{~d}$. A 100-150 mg sample of spleen tissue was excised and immediately frozen at $-20^{\circ}$ for subsequent fatty acid analysis.

\section{Lymphocyte proliferation assay}

Spleens from untreated and 4 or $12 \mathrm{~d}$ treated animals were teased apart in RPMI 1640 in petri dishes to release cells. The resulting cell suspension was centrifuged at $250 \mathrm{~g}$ and the pellet washed in RPMI 1640. Erythrocytes were lysed with $\mathrm{Tris}-\mathrm{NH}_{4} \mathrm{Cl}$ and the cells resuspended in RPMI plus $5 \%(\mathrm{v} / \mathrm{v})$ fetal calf serum (FCS). Cells were counted using an improved Neubauer haemocytometer (BDH, Lutterworth, Leics.) and found to be $>95 \%$ viable as determined by phase-contrast microscopy. Cells and Con A (Sigma) (100 $\mu \mathrm{l} \mathrm{each)}$ 
were transferred into flat-bottomed 96 multiwell plates (Nunc, Kamstrup, Denmark) to give a final cell density of $5 \times 10^{6} \mathrm{cells} / \mathrm{ml}$ and Con-A concentrations of $0,1,2$, or $4 \mu \mathrm{g} / \mathrm{ml}$. Antibiotics were also included as $125 \mathrm{mg} / \mathrm{ml}$ ampicillin and $125 \mathrm{mg} / \mathrm{ml}$ cloxacillin. Plates were left undisturbed for $48 \mathrm{~h}$ at which time $37 \mathrm{~Bq} /$ well of $\left[{ }^{3} \mathrm{H}\right]$ thymidine (Amersham International Ltd., Bucks.) was added and the cultures left for a further $8 \mathrm{~h}$. Cells were collected by cell harvester (Skatron, Norway) and counted for $1 \mathrm{~min} / \mathrm{sample}$ on a liquid scintillation analyser (Tri-Carb 2000CA Packard, Pangbourne, Berks.). Results are expressed as a stimulation index which is the mean counts per minute (CPM) of Con Astimulated cultures divided by the mean CPM of cultures without Con A.

\section{Spleen lymphocyte sub-set analysis}

Splenic lymphocytes, prepared as above, were incubated with the following primary mouse monoclonal antibodies to rat lymphocytes obtained from Serotec (Oxford, Oxon.): MRC OX-8 (suppressor/cytotoxic T-cells, CD8) and W3/25 (helper T-cells, CD4). Primary antibodies were diluted in phosphate-buffered saline (PBS) at 1:100. The secondary antibody ST-AR 9 (Serotec), a $\mathrm{F}(\mathrm{ab})_{2}$ rabbit anti-mouse immunoglobulin $\mathrm{G}$ (IgG) fluorescein isothiocyanate conjugate (FITC), was diluted 1:50 with PBS. Splenic cells prepared from control and treated animals in RPMI 1640 plus $5 \%$ (v/v) FCS, at $10 \times 10^{6} \mathrm{cells} / \mathrm{ml}$, were washed twice and resuspended at the same density with PBS. Portions of $100 \mu \mathrm{l}\left(10^{6}\right.$ cells) were transferred to cylindrical round-bottomed plastic centrifuge tubes, spun down in multi-tube carriers at $1000 \mathrm{rev} . / \mathrm{min}$ on a IEC centra-7 centrifuge (International Equipment Company, Dunstable, Beds.), resuspended in $0.5 \mathrm{ml}$ PBS and centrifuged for $5 \mathrm{~min}$, and the supernatant fractions removed using sterile plastic Pasteur pipettes. To the pelleted cells $50 \mu \mathrm{l}$ primary antibody was added ( $50 \mu \mathrm{l} / 10^{6}$ cells), the cells were resuspended and incubated for $15 \mathrm{~min}$ at room temperature. The antibodies ST-AR 9 (anti-mouse IgG) and W6/32 (anti-HLA (ABC) Class I) were also used as negative controls at the primary antibody stage. The cells were washed in $1 \mathrm{ml}$ PBS, centrifuged, and to the cell pellet the secondary antibody (FITC) was added at $50 \mu 1$, incubated at room temperature for $15 \mathrm{~min}$ and washed and centrifuged twice with $1 \mathrm{ml}$ PBS. The percentage of positive cells was obtained from analysis of $2 \times 10^{3}$ cells using a FACScan flow cytometer (Becton Dickinson, Oxford, Oxon.).

\section{Spleen lipid extraction and separation}

Lipids were extracted from spleen tissue by the method of Folch et al. (1957). Individual phosphoglycerides from the total lipid extract were separated by TLC on precoated silica gel $60 \mathrm{~A}$ (Whatman, Maidstone, Kent) plates $(200 \times 200 \mathrm{~mm})$ and identified by co-migration with bovine sources of $\mathrm{L}-\alpha$-phosphatidylcholine and $\mathrm{L}-\alpha$-phosphatidylethanolamine (Sigma). Plates were developed in chloroform-methanol-water $(65: 24: 4$, by vol.) containing 2,6-di-t-butyl-4-methylphenol $(0 \cdot 1 \mathrm{~g} / 1)$ and the resulting phosphoglycerides visualized under a u.v. lamp (Camag TL-900, Camlab Ltd., Cambridge, Cambs.) after spraying the dried plate with 2,7-dichlorofluorescein $(1 \mathrm{ml} / 1$ in methanol). Fatty acid separation and identification were as described previously (Harbige et al. 1990). Briefly, they involved transmethylation of phosphoglyceride fatty acids at $70^{\circ}$ followed by petroleum spirit extraction, evaporation to dryness and injection on to a GLC column. The chromatograph utilized was a Pye Unicam model 204 equipped with dual flame-ionization detectors, the column was a $25 \mathrm{~m} \times 0.53 \mathrm{~nm} \times 2 \mu \mathrm{m}$ polyethylene glycol (Carbowax 20M immob) capillary column. Fatty acid methyl esters were identified by equivalent chain length (ECL) values (Ackman, 1969) and comparison with authentic standards (Sigma) and quantified as percentage total peak areas for fatty acid methyl esters between palmitic (16:0) and docosahexaenoic (22:6n-3) acids. 


\section{Statistical analysis}

Differences in the incidence of clinical (score 1 and above) and histological disease between control EAE and treatments were assessed using $\chi^{2}$ analysis. Differences in the clinical severity between treatment groups were compared using the Wilcoxon sum of ranks test. Differences between the effect of treatment on mitogen stimulation were analysed using Student's unpaired $t$ test. Fatty acid differences were assessed using one-way ANOVA and when significant, differences between the means were evaluated by Student's unpaired $t$ test (Clarke, 1982).

\section{RESULTS}

Incidence of clinical experimental autoimmune encephalomyelitis in safflower-seed-and fungal-oil-treated Lewis rats

The incidence of EAE in rats inoculated with CNS homogenate, and treated $7 \mathrm{~d}$ later with safflower-seed oil at $500 \mathrm{mg}$ linoleic acid $/ \mathrm{kg}$ body weight or fungal oil at $500 \mathrm{mg} \gamma$-linolenic acid/ $\mathrm{kg}$ body weight are shown in Figs 1 and 2 respectively. There were no significant differences in the clinical incidence of EAE between safflower-seed-oil-treated and untreated EAE rats (Fig. 1). Fungal-oil treatment markedly reduced the incidence of EAE compared with control EAE animals and gave full protection against the clinical disease (Fig. 2).

\section{Dose-response effects of safflower-seed oil on clinical experimental autoimmune encephalomyelitis}

Dose-response incidence for EAE to linoleic-acid-rich safflower-seed oil (mg/ $\mathrm{kg}$ body weight) is shown in Table 3 . These were not significantly different for untreated EAE and animals treated with 500 and $750 \mathrm{mg}$ linoleic acid $/ \mathrm{kg}$ body weight. Differences in incidence between the untreated EAE and the $1000 \mathrm{mg}$ linoleic acid $/ \mathrm{kg}$ group at day 21 were, however, significantly lower $(P<0 \cdot 005)$. In contrast, the dose-response curves for the effect of safflower-seed oil on EAE clinical severity clearly show a dose-related effect (Fig. 3). Both the 750 and $1000 \mathrm{mg} / \mathrm{kg}$ dose groups had marked reductions in mean severity score throughout the clinical disease phase. Additionally, the $1000 \mathrm{mg} / \mathrm{kg}$ group had a faster recovery rate than the $750 \mathrm{mg} / \mathrm{kg}$ group and in comparison with the untreated $\mathrm{EAE}$ group at the height of clinical severity (day 17) had a significantly lower $(P<0.005)$ severity score. There was no difference in body-weight loss between the group treated with $1000 \mathrm{mg}$ linoleic acid $/ \mathrm{kg}$ and untreated EAE (results not shown).

Dose-response effects of fungal oil on clinical experimental autoimmune encephalomyelitis Table 4 shows the effect of $\gamma$-linolenic-acid-rich fungal oil at 200,500 and $1000 \mathrm{mg} / \mathrm{kg}$ body weight on the clinical incidence of EAE. Fungal-oil treatment at $500 \mathrm{mg} \gamma$-linolenic acid $/ \mathrm{kg}$ body weight protected against the development of clinical EAE, confirming the above result at the same dose level (Fig. 2). At doses of 200 and $1000 \mathrm{mg} \gamma$-linolenic $\mathrm{acid} / \mathrm{kg}$, the fungal oil was only effective in delaying the onset of clinical disease by $2-3 \mathrm{~d}$ compared with incidence data recorded for untreated EAE. Clinical severity scores showed no apparent difference in the severity of the disease in the groups treated with 200 and $1000 \mathrm{mg} / \mathrm{kg}$ to that of untreated EAE.

\section{Histopathological findings in safflower-seed-and fungal-oil-treated Lewis rats}

Animals showing severe clinical signs of EAE (control untreated group) were observed to have mononuclear cell infiltration and perivascular cuffing in spinal cord and cerebellum (Table 5, Plate 1). In marked contrast, rats treated with fungal oil (500 $\mathrm{mg} \gamma$-linolenic acid $/ \mathrm{kg}$ body weight) had a total absence of mononuclear infiltration (Table 5, Plate 2). Far 


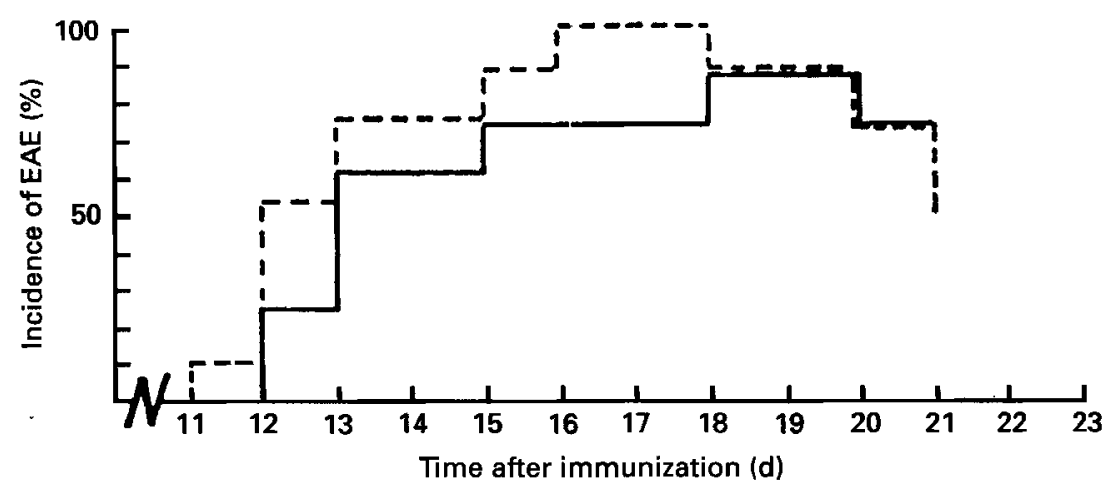

Fig. 1. Effect of safflower (Carthamus tinctorius)-seed oil treatment ( $500 \mathrm{mg}$ linoleic acid $/ \mathrm{kg}$ body weight) on the incidence of experimental autoimmune encephalomyelitis (EAE) in Lewis rats. $(-)$, Control group, $n 8 ;(---)$, treated group, $n$ 9. For details of diets and procedures see Tables 1 and 2 and p. 702 .

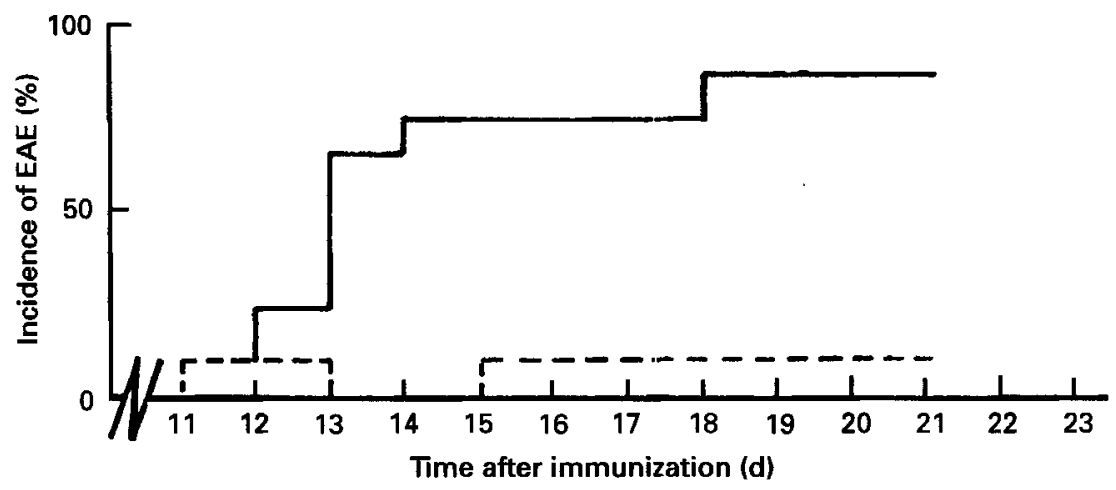

Fig. 2. Effect of fungal (Mucor javanicus) oil treatment ( $500 \mathrm{mg} \gamma$-linolenic acid $/ \mathrm{kg}$ body weight) on the incidence of experimental autoimmune encephalomyelitis (EAE) in Lewis rats. $(-)$, Control group, $n 8 ;(---)$, treated group, $n$ 10. For details of diets and procedures, see Tables 1 and 2 and p. 702 .

Table 3. Dose-response incidence for experimental autoimmune encephalomyelitis to linoleic acid-rich safflower (Carthamus tinctorius)-seed oil in Lewis rats

\begin{tabular}{ccccc}
\hline \hline & & \multicolumn{3}{c}{$\begin{array}{c}\text { Safflower-seed oil linoleic acid dose } \\
\text { (mg/kg body wt) }\end{array}$} \\
\cline { 3 - 5 } Day & Controls & 500 & 750 & 1000 \\
\hline 11 & $1 / 10$ & $1 / 9$ & $1 / 5$ & $0 / 10$ \\
13 & $8 / 10$ & $7 / 9$ & $2 / 5$ & $6 / 10$ \\
15 & $10 / 10$ & $8 / 9$ & $3 / 5$ & $6 / 10$ \\
17 & $9 / 10$ & $9 / 9$ & $5 / 5$ & $7 / 10$ \\
19 & $10 / 10$ & $8 / 9$ & $3 / 5$ & $5 / 10$ \\
21 & $9 / 10$ & $5 / 9$ & $2 / 5$ & $2 / 10^{* *}$ \\
\hline
\end{tabular}

** Significantly different from control value, $P<0.005$. 


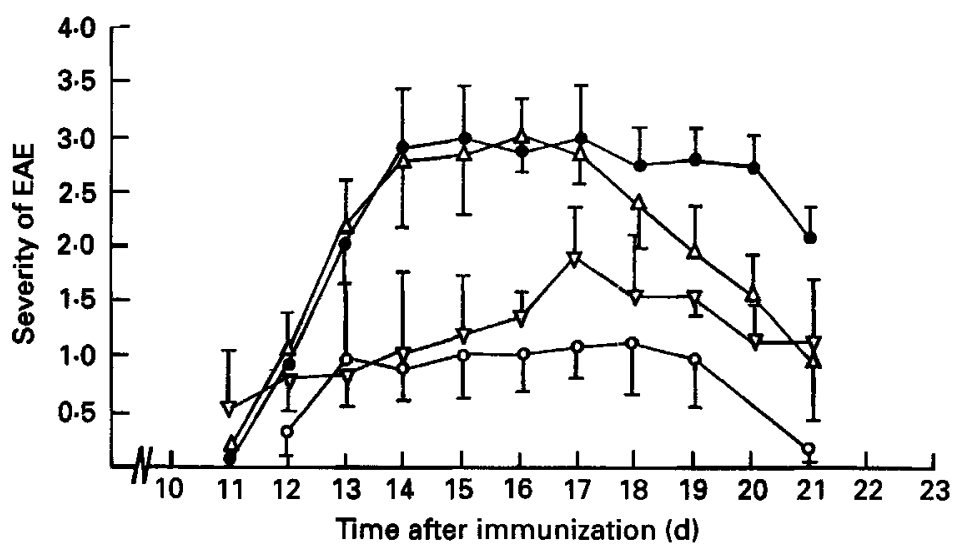

Fig. 3. Effect of dose of safflower (Carthamus tinctorius)-seed oil on the severity of experimental autoimmune encephalomyelitis (EAE) in Lewis rats. (O), Control, $n 10 ;(\triangle), 500 \mathrm{mg}$ linoleic acid/kg body weight, $n 9 ;(\nabla)$, $750 \mathrm{mg}$ linoleic acid $/ \mathrm{kg}$ body weight, $n 5 ;(O), 1000 \mathrm{mg}$ linoleic acid $/ \mathrm{kg}$ body weight, $n 10$. Clinical severity criteria: score 1, limp tail (loss of tail tonicity); score 2, weakness of hindlimbs (one or both); score 3, distinctive involvement of both hindlimbs; score 4, complete paralysis of hindlimbs; score 5, as 4 plus incontinence and/or front limb paralysis. For details of diets see Tables 1 and 2.

Table 4. Dose-response incidence for experimental autoimmune encephalomyelitis to $\gamma$ linolenic-acid-rich fungal (Mucor javanicus) oil in Lewis rats

\begin{tabular}{|c|c|c|c|c|}
\hline \multirow[b]{2}{*}{ Day } & \multirow[b]{2}{*}{ Controls } & \multicolumn{3}{|c|}{$\begin{array}{l}\text { Fungal oil } \gamma \text {-linolenic acid dose } \\
\text { (mg/kg body wt) }\end{array}$} \\
\hline & & 200 & 500 & 1000 \\
\hline 11 & $1 / 10$ & $0 / 5$ & $0 / 6$ & $0 / 5$ \\
\hline 13 & $8 / 10$ & $1 / 5^{*}$ & $0 / 6^{* *}$ & $2 / 5$ \\
\hline 15 & $10 / 10$ & $2 / 5$ & $0 / 6^{* *}$ & $4 / 5$ \\
\hline 17 & $9 / 10$ & $3 / 5$ & $1 / 6^{* *}$ & $4 / 5$ \\
\hline 19 & $10 / 10$ & $3 / 5$ & $1 / 6^{* *}$ & $5 / 5$ \\
\hline 21 & $9 / 10$ & $4 / 5$ & $1 / 6 * *$ & $4 / 5$ \\
\hline
\end{tabular}

Values were significantly different from control value, $* P<0.05, * * P<0.005$

Table 5. Histological findings in Lewis rats with experimental autoimmune encephalomyelitis treated with fungal (Mucor javanicus) oil $(500 \mathrm{mg} \gamma$-linolenic acid/kg body weight) or safflower (Carthamus tinctorius)-seed oil (1000 mg linoleic acid/kg body weight) $\dagger$

\begin{tabular}{llc}
\hline \hline Treatment & $\begin{array}{c}\text { Number of animals } \\
\text { showing histologic } \\
\text { signs of disease }\end{array}$ & $\begin{array}{c}\text { Severity } \\
\text { of lesions } \ddagger\end{array}$ \\
\hline Control & $8 / 8$ & +++ \\
Fungal oil & $0 / 8^{* * *}$ & - \\
Safflower-seed oil & $5 / 9^{*}$ & + \\
\hline
\end{tabular}

Values were significantly different from control value, $* P<0.05, * * * P<0.001$.

$\dagger$ For details of diets and procedures, see Tables 1 and 2 and pp. 702-703.

$\ddagger-$, no lesions; + , up to four or five lesions on the entire slide; +++ , lesions in each of several different lowpower fields. 


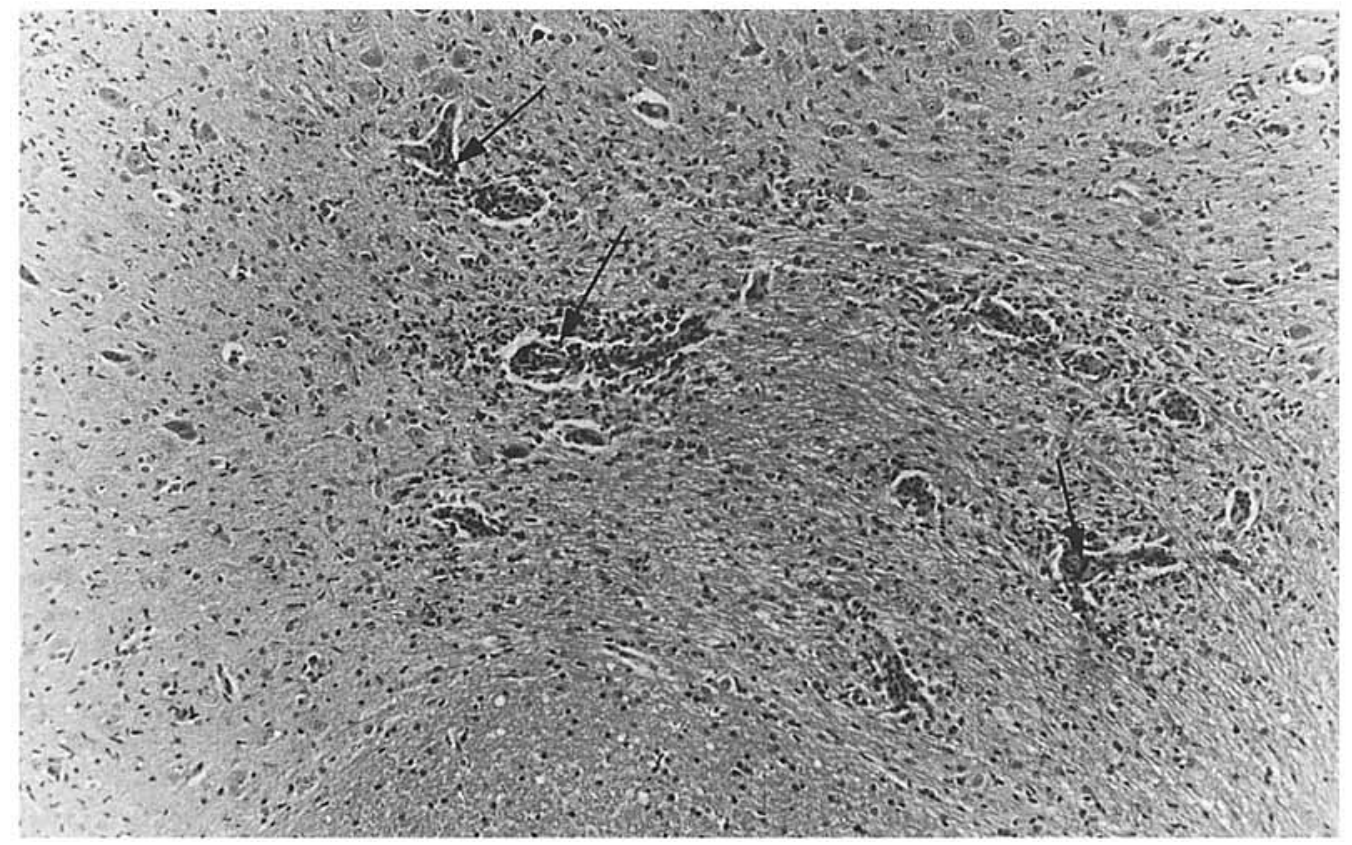

Plate 1. Histological features of the cerebellum from a Lewis rat exhibiting clinical experimental autoimmune encephalomyelitis ( $5 \mu \mathrm{m}$ section $\times 100$, haematoxylin and eosin stain). Note the mononuclear leucocyte infiltration particularly around the blood vessels (arrows).

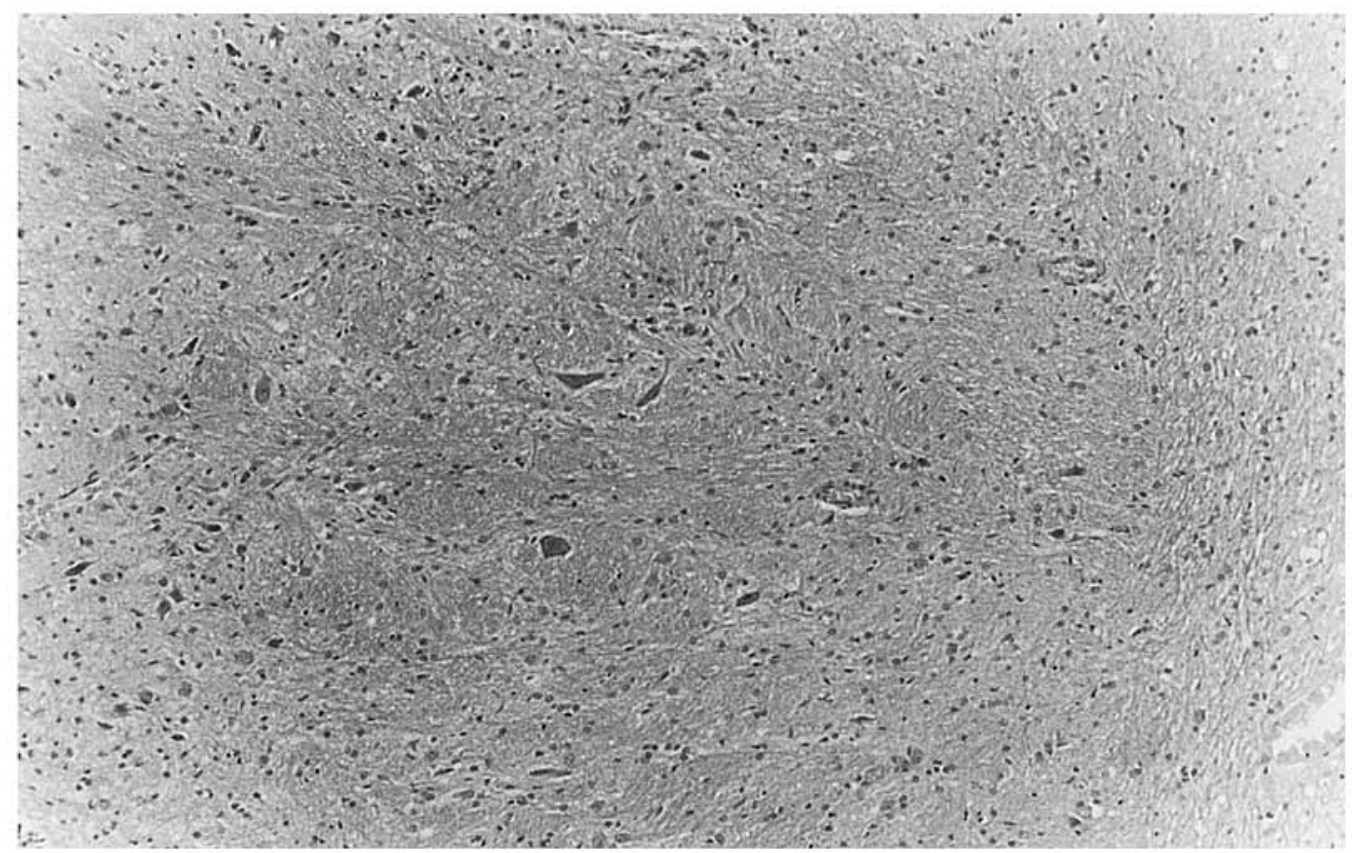

Plate 2. Histological features of the cerebellum from a Lewis rat inoculated with CNS-CFA and treated with fungal (Mucor javanicus) oil at $500 \mathrm{mg} \gamma$-linolenic acid $/ \mathrm{kg}$ body weight showing no mononuclear leucocyte infiltration ( $5 \mu \mathrm{m}$ section $\times 100$, haematoxylin and eosin stain). For details of procedures, see p. 702. 


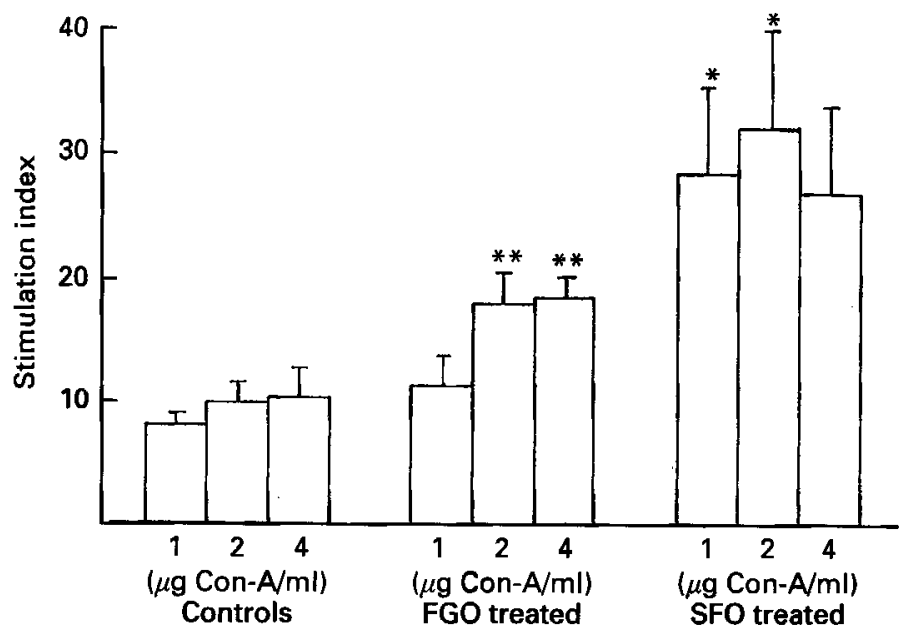

Fig. 4. Effect of safflower (Carthamus tinctorius)-seed oil (SFO) and fungal (Mucor javanicus) oil (FGO) treatments for $4 \mathrm{~d}$ on concanavalin A (Con-A)-stimulated proliferation of rat spleen lymphocytes. Values are means for six to eight animals per group, with standard deviations represented by vertical bars. The stimulation index is given by: mean counts/min (cpm) of Con-A-stimulated cultures divided by the mean cpm of cultures without Con-A. Mean values were significantly different from control: ${ }^{*} P<0.05,{ }^{* *} P<0.02$. For details of diets, see Tables 1 and 2 , and p. 703 .

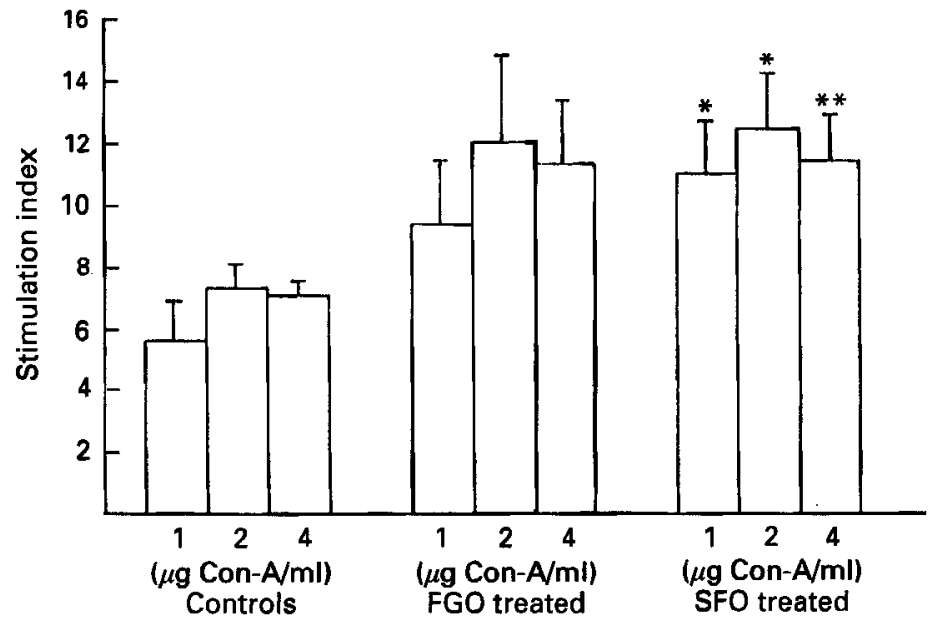

Fig. 5. Effect of safflower (Carthamus tinctorius)-seed oil (SFO) and fungal (Mucor javanicus) oil (FGO) treatments for $12 \mathrm{~d}$ on concanavalin A (Con-A)-stimulated proliferation of rat spleen lymphocytes. Values are means for five animals per group, with standard deviations represented by vertical bars. The stimulation index is given by: mean counts/min (cpm) of Con-A-stimulated cultures divided by the mean $\mathrm{cpm}$ of cultures without Con-A. Mean values were significantly different from control: ${ }^{*} P<0.05$, ${ }^{* *} P<0.02$. For details of diets, see Tables 1 and 2 , and p. 703 .

fewer mononuclear infiltrated perivascular sites were observed in safflower-seed-oil(1000 $\mathrm{mg}$ linoleic acid $/ \mathrm{kg}$ body weight) treated animals (Table 5).

\section{Lymphocyte stimulation indices $4 d$ after oil treatments}

At day 4, the spleen lymphoproliferative responses of safflower-seed-oil-treated rats, at Con A concentrations of 1,2 and $4 \mu \mathrm{g} / \mathrm{ml}$, were increased 3.4-, 3·2- and 2·6-fold respectively 
Table 6. Effect of linoleic-acid-rich safflower (Carthamus tinctorius)-seed oil treatment on spleen lymphocyte subsets in Lewis rats*†

(Mean values and standard deviations)

\begin{tabular}{|c|c|c|c|c|c|c|c|c|c|}
\hline \multirow{3}{*}{$\begin{array}{l}\text { Subset } \\
\text { determinants }\end{array}$} & \multicolumn{9}{|c|}{ Length of safflower-seed oil treatment (d) } \\
\hline & \multicolumn{3}{|c|}{$\mathbf{0}$} & \multicolumn{3}{|c|}{4} & \multicolumn{3}{|c|}{12} \\
\hline & Mean & $n$ & SD & Mean & $n$ & SD & Mean & $n$ & SD \\
\hline CD4 & $63 \cdot 3$ & 5 & $1 \cdot 9$ & $61 \cdot 1$ & 3 & $2 \cdot 2$ & $63 \cdot 7$ & 5 & $4 \cdot 1$ \\
\hline CD8 & $27 \cdot 7$ & 5 & $5 \cdot 6$ & $19 \cdot 6$ & 3 & $4 \cdot 0$ & $24 \cdot 7$ & 5 & $2 \cdot 7$ \\
\hline CD4: CD8 & $2 \cdot 3$ & 5 & $0 \cdot 4$ & $2 \cdot 8$ & 3 & 0.6 & 2.6 & 5 & 0.3 \\
\hline
\end{tabular}

* Values are expressed as percentages of $2 \times 10^{3}$ cells.

$\dagger$ For details of diets and procedures, see Tables 1 and 2 and pp. 702-704.

compared with untreated control rats (Fig. 4). These increases were statistically significant at $1 \mu \mathrm{g} / \mathrm{ml}(P<0.02)$ and $2 \mu \mathrm{g} / \mathrm{ml}(P<0.05)$ but not $4 \mu \mathrm{g} / \mathrm{ml}$. Fungal-oil-treated rats compared with corresponding controls had increased T-cell lymphoproliferative responses to Con A at $2 \mu \mathrm{g} / \mathrm{ml}(P<0.025)$ and $4 \mu \mathrm{g} / \mathrm{ml}(P<0.02)$ (Fig. 4). In contrast to safflowerseed-oil-treated rats the mean stimulation indices for fungal-oil-treated rats at 1,2 and $3 \mu \mathrm{g}$ Con A/ml were only 1.3-, 1.8- and 1.7-fold higher than the control values, indicating a greater enhancement of spleen T-cell responses by safflower-seed oil, $4 \mathrm{~d}$ after treatment. No statistically significant differences between safflower-seed- and fungal-oil stimulation indices were observed.

\section{Lymphocyte stimulation indices $12 d$ after oil treatments}

Spleen T-lymphocyte lymphoproliferative responses to Con A after $12 \mathrm{~d}$ safflower-seedand fungal-oil treatment are shown in Fig. 5. Safflower-seed-oil treatment resulted in statistically significant increases in the $1 \mu \mathrm{g} / \mathrm{ml}(P<0.05), 2 \mu \mathrm{g} / \mathrm{ml}(P<0.05)$ and $4 \mu \mathrm{g} / \mathrm{ml}$ $(P<0.025)$ Con A concentrations used in the assay. No significant differences between fungal-oil-treated animals and controls were observed. Nonetheless, the mean stimulation indices for fungal oil were of a similar magnitude in the 2 and $4 \mu \mathrm{g} \mathrm{Con} \mathrm{A/ml} \mathrm{to} \mathrm{that} \mathrm{of}$ the safflower-seed-oil treatment. However, because of a higher degree of variation they were not statistically significant.

Phenotypic characteristics of spleen lymphocytes from oil-treated rats

No statistically significant changes in the cell surface determinants CD4 (W3/25) and CD8 (OX-8) were detected after $4 \mathrm{~d}$ safflower-seed-oil treatment (Table 6); there was, however, a $25 \%$ decrease in the mean proportion of $\mathrm{CD}^{+}$cells. There were no statistically significant changes after $12 \mathrm{~d}$ safflower-seed-oil treatment in the proportions of $\mathrm{CD}^{+}$and $\mathrm{CD} 8^{+}$cells (Table 6).

Results on cells obtained from rats treated for $4 \mathrm{~d}$ with fungal oil are shown in Table 7 . The major shift in cell proportions after $4 \mathrm{~d}$ fungal-oil treatment was a decrease in the $\mathrm{CD}^{+}$ cells by $23 \%$ relative to controls. Proportions of $\mathrm{CD}^{+}$and $\mathrm{CD} 8^{+}$cells obtained from rats treated for $12 \mathrm{~d}$ with fungal oil compared with control rats had a decreased mean proportion of $\mathrm{CD} 8^{+}$cells by $17 \%$. However, none of these changes were statistically significant. 
Table 7. Effect of $\gamma$-linolenic acid-rich fungal oil treatment on spleen lymphocyte subsets in Lewis rats*†

(Mean values and standard deviations)

\begin{tabular}{|c|c|c|c|c|c|c|c|c|c|}
\hline \multirow{3}{*}{$\begin{array}{l}\text { Subset } \\
\text { determinants }\end{array}$} & \multicolumn{9}{|c|}{ Length of fungal oil treatment (d) } \\
\hline & \multicolumn{3}{|c|}{0} & \multicolumn{3}{|c|}{4} & \multicolumn{3}{|c|}{12} \\
\hline & Mean & $n$ & SD & Mean & $n$ & SD & Mean & $n$ & SD \\
\hline$\overline{\mathrm{CD} 4}$ & $63 \cdot 3$ & 5 & 1.9 & $65 \cdot 0$ & 2 & & 66.6 & 5 & 3.0 \\
\hline CD8 & $27 \cdot 7$ & 5 & $5 \cdot 6$ & $20-2$ & 2 & & 21.8 & 5 & $4 \cdot 4$ \\
\hline CD4:CD8 & $2 \cdot 3$ & 5 & 0.4 & $3 \cdot 2$ & 2 & & 3.1 & 5 & 0.7 \\
\hline
\end{tabular}

* Values are expressed as a percentage of $2 \times 10^{3}$ cells.

$\dagger$ For details of diets and procedures, see Tables 1 and 2 and pp. 702-704.

Table 8. Effect of fungal (Mucor javanicus) oil administration on spleen choline (CPG) and ethanolamine (EPG) phosphoglyceride fatty acids ( $\mathrm{g} / 100 \mathrm{~g}$ total fatty acids measured) in Lewis rats $\dagger$

(Mean values and standard deviations for three to four rats)

\begin{tabular}{|c|c|c|c|c|c|c|c|c|}
\hline & \multicolumn{2}{|c|}{ Day 0} & \multicolumn{2}{|c|}{ Day 4} & \multicolumn{2}{|c|}{ Day 8} & \multicolumn{2}{|c|}{ Day 12} \\
\hline & Mean & SD & Mean & SD & Mean & SD & Mean & SD \\
\hline \multicolumn{9}{|l|}{ CPG fatty acid } \\
\hline $18: 2 n-6$ & $3 \cdot 8$ & $1 \cdot 2$ & $5 \cdot 2$ & $1 \cdot 6$ & $4 \cdot 1$ & $1 \cdot 7$ & $4 \cdot 2$ & $0 \cdot 9$ \\
\hline $18: 3 n-6$ & 0.3 & 0.1 & 0.3 & $0 \cdot 1$ & 0.2 & 0.01 & 0.5 & 0.2 \\
\hline $20: 2 n-6$ & 0.6 & 0.04 & 0.6 & 0.04 & 0.5 & 0.1 & $0 \cdot 8$ & $0 \cdot 1$ \\
\hline $20: 3 n-6$ & 0.6 & 0.2 & $1 \cdot 2^{* *}$ & 0.07 & $1 \cdot 0$ & $0 \cdot 2$ & $1 \cdot 3^{*}$ & $0 \cdot 2$ \\
\hline $20: 4 n-6$ & $7 \cdot 3$ & $2 \cdot 3$ & $8 \cdot 5$ & $1 \cdot 5$ & 8.0 & $1 \cdot 1$ & $9 \cdot 8$ & 1.6 \\
\hline $20: 4 n-6 / 20: 3 n-6$ & $12 \cdot 7$ & 1.7 & $7 \cdot 2 * *$ & $1 \cdot 2$ & $7 \cdot 0^{* *}$ & $0 \cdot 4$ & $7 \cdot 8^{* * *}$ & 0.5 \\
\hline \multicolumn{9}{|l|}{ EPG fatty acid } \\
\hline $18: 2 n-6$ & 40 & 0.4 & $3 \cdot 9$ & 0.9 & 3.8 & 1.0 & $4 \cdot 6$ & 0.6 \\
\hline $18: 3 n-6$ & $0 \cdot 3$ & 0.3 & $0 \cdot 3$ & 0.2 & 0.3 & $0 \cdot 2$ & $0 \cdot 1$ & 0.02 \\
\hline $20: 2 n-6$ & 0.7 & 0.2 & 0.5 & 0.1 & 0.6 & 0.08 & 0.5 & 0.03 \\
\hline $20: 3 n-6$ & 0.4 & $0 \cdot 1$ & $1 \cdot 0^{* *}$ & 0.08 & $0.9^{*}$ & 0.08 & $1 \cdot 2 * *$ & 0.1 \\
\hline $20: 4 n-6$ & $17 \cdot 1$ & $3 \cdot 2$ & $24 \cdot 5^{*}$ & $2 \cdot 4$ & $23 \cdot 0$ & $4 \cdot 2$ & $26-3^{*}$ & 1.9 \\
\hline $20: 4 n-6 / 20: 3 n-6$ & $42 \cdot 8$ & $20 \cdot 5$ & $24 \cdot 3$ & $1 \cdot 1$ & $24 \cdot 2$ & $2 \cdot 8$ & $22 \cdot 3$ & 1.5 \\
\hline
\end{tabular}

Mean values were significantly different from day 0 values, ${ }^{*} P<0.05,{ }^{* *} P<0.01$.

$\dagger$ For details of treatment and procedures, see Tables 1 and 2 and pp. 702-704.

\section{Spleen phosphoglyceride fatty acids from oil-treated rats}

Rats given oral fungal oil had a mean increase in the proportion of dihomo- $\gamma$-linolenic $(20: 3 n-6)$ and arachidonic $(20: 4 n-6)$ acids in spleen ethanolamine phosphoglycerides at day 4 (20:3n-6, $P<0.005$ and $20: 4 n-6, P<0.025)$, day $8(20: 3 n-6, P<0.025$ and $20: 4 n-6, P>$ $0.05)$, and at day $12(20: 3 n-6, P<0.005,20: 4 n-6, P<0.025)$ compared with day 0 samples (Table 8). Rats orally administered safflower-seed oil had mean increases in the proportion of dihomo- $\gamma$-linolenic acid in the spleen ethanolamine phosphoglycerides at day $4(P<$ $0.025)$, day $8(P>0.05)$ and day $12(P<0.025)$ compared with the corresponding baseline 
Table 9. Effect of safflower (Carthamus tinctorius)-seed oil administration on spleen choline $(C P G)$ and ethanolamine $(E P G)$ phosphoglyceride fatty acids $(\mathrm{g} / 100 \mathrm{~g}$ total fatty acids measured) in Lewis rats $\dagger$

(Mean values and standard deviations for three to four rats)

\begin{tabular}{|c|c|c|c|c|c|c|c|c|}
\hline & \multicolumn{2}{|c|}{ Day 0} & \multicolumn{2}{|c|}{ Day 4} & \multicolumn{2}{|c|}{ Day 8} & \multicolumn{2}{|c|}{ Day 12} \\
\hline & Mean & SD & Mean & SD & Mean & SD & Mean & SD \\
\hline \multicolumn{9}{|l|}{ CPG fatty acid } \\
\hline $18: 2 n-6$ & 3.8 & $1 \cdot 2$ & 5.8 & $1 \cdot 5$ & 5.9 & $1 \cdot 2$ & $5 \cdot 5$ & $1 \cdot 6$ \\
\hline $18: 3 n-6$ & 0.3 & 0.1 & 0.2 & 0.02 & 0.2 & 0.03 & 0.2 & 0.02 \\
\hline $20: 2 n-6$ & 0.6 & 0.04 & 0.6 & 0.02 & 0.7 & $0 \cdot 2$ & $0 \cdot 6$ & $0 \cdot 1$ \\
\hline $20: 3 n-6$ & 0.6 & 0.2 & 0.5 & 0.06 & 0.7 & 0.02 & 0.5 & 0.05 \\
\hline $20: 4 n-6$ & $7 \cdot 3$ & $2 \cdot 3$ & $6 \cdot 3$ & 0.9 & $7 \cdot 0$ & 0.05 & $7 \cdot 0$ & $1 \cdot 0$ \\
\hline $20: 4 n-6 / 20: 3 n-6$ & 12.74 & 1.7 & 11.6 & $0 \cdot 6$ & $10 \cdot 3$ & $1 \cdot 2$ & $12 \cdot 5$ & 0.5 \\
\hline \multicolumn{9}{|l|}{ EPG fatty acid } \\
\hline $18: 2 n-6$ & $4 \cdot 0$ & 0.4 & $5 \cdot 3$ & 1.4 & $5 \cdot 4$ & $1 \cdot 6$ & $5 \cdot 1$ & $1 \cdot 0$ \\
\hline $18: 3 n-6$ & 0.3 & 0.3 & 0.3 & $0 \cdot 1$ & 0.2 & 0.01 & $0 \cdot 3$ & 0.2 \\
\hline $20: 2 n-6$ & 0.7 & 0.2 & 0.6 & $0 \cdot 1$ & 0.9 & 0.4 & $0 \cdot 6$ & 0.02 \\
\hline $20: 3 n-6$ & 0.4 & 0.1 & $0.7 *$ & $0 \cdot 1$ & 0.9 & 0.3 & $0.7^{*}$ & 0.1 \\
\hline $20: 4 n-6$ & $17 \cdot 1$ & $3 \cdot 2$ & $22 \cdot 0$ & $2 \cdot 6$ & $21 \cdot 1$ & $1 \cdot 4$ & $22 \cdot 0$ & $3 \cdot 0$ \\
\hline $20: 4 n-6 / 20: 3 n-6$ & 42.8 & 20.5 & 30.0 & 3.7 & $23 \cdot 4$ & $8 \cdot 4$ & $33 \cdot 3$ & 0.35 \\
\hline
\end{tabular}

* Mean values were significantly different from Day $0, P<0.025$.

$\dagger$ For details of diets and procedures, see Tables 1 and 2 and pp. 702-704.

day 0 samples (Table 9). Spleen choline phosphoglycerides from rats orally administered safflower-seed oil did not show any major changes in fatty acid composition compared with day 0 samples (Table 9). Animals given oral fungal oil had increases in the mean proportion of dihomo- $\gamma$-linolenic acid at day $4(P<0.01)$, day $8(P>0.05)$, and day $12(P<0.025)$ compared with day 0 samples. There were also significant decreases in the $20: 4 n-6 / 20: 3 n-6$ ratio in fungal-oil-administered animals at day $4(P<0.01)$, day $8(P<0.005)$ and day 12 $(P<0.009)$ in the choline phosphoglycerides (Table 8).

\section{DISCUSSION}

This study has investigated the effects of essential-fatty-acid-rich oils on the clinical and histological aspects of rat EAE, and in healthy rats examined their effects on cellular immunological variables. Treatment of Lewis-rat EAE with $\boldsymbol{n - 6}$ fatty-acid-rich safflowerseed and fungal oils was clearly beneficial in terms of the clinical and histopathological manifestations of the disease. Linoleic-acid-rich safflower-seed-oil treatment had a dosedependent action on the clinical severity of EAE, although not abolishing it, at doses of 750 and $1000 \mathrm{mg}$ linoleic acid $/ \mathrm{kg}$ body weight. Full protection against EAE was achieved with fungal oil at a dose of $500 \mathrm{mg} \gamma$-linolenic acid $/ \mathrm{kg}$ body weight. At 200 and $1000 \mathrm{mg} \gamma$ linolenic acid $/ \mathrm{kg}$ body weight, however, fungal oil was only effective in delaying the onset of clinical disease by 2-3 d. Full clinical protection by fungal oil was associated with a marked absence of CNS mononuclear cell infiltration whilst a lower clinical severity induced by safflower-seed oil corresponded to fewer CNS mononuclear cell infiltrates. The strikingly protective effect of fungal oil at $500 \mathrm{mg} \gamma$-linolenic acid $/ \mathrm{kg}$ body weight is a new and important finding.

Results obtained in the present study demonstrate a dose-dependency effect of linoleicacid-rich safflower-seed oil on the clinical severity of rat EAE. Based on the partial 
suppression of clinical incidence, Stackpoole \& Mertin (1981) reported dose-dependent effects of a high-linoleic and low- $\gamma$-linolenic-acid oil $(73 \mathrm{~g}$ linoleic and $8 \mathrm{~g} \gamma$-linolenic acid/100 g oil) on rat EAE. Linoleic acid may only be able to exert a high suppressional effect on EAE of a low clinical severity. This might explain the differences in observations for suppression of severity observed in the present study as opposed to incidence reported by Stackpoole \& Mertin (1981) whose control EAE animals did show lower clinical severity signs than those reported here. It is also possible that the small $\gamma$-linolenic acid content of the oil used by Stackpoole \& Mertin (1981) might be a significant factor in EAE suppression, although the present findings suggest that this would only have delayed the onset of EAE.

Mertin et al. (1984, 1985) proposed a bell-shaped dose-response action of E-series prostaglandins and their precursors on cell-mediated immune responses. However, the ' $U$ ' shaped incidence dose response for EAE to $\gamma$-linolenic-acid-rich fungal oil observed in the present study does not appear to fit that predicted by Mertin et al. $(1984,1985)$. Furthermore, suppression of guinea-pig EAE (Meade et al. 1978) required far less linoleic acid (125-175 $\mathrm{mg} / \mathrm{kg}$ body weight) than in the rat (750-1000 $\mathrm{mg} / \mathrm{kg}$ body weight), even though the guinea-pig is a much slower 'desaturator' of linoleic acid (Crawford et al. 1977). This suggests that essential fatty acids act on cellular immunological reactions via mechanisms other than just their oxygenated eicosanoid metabolites.

Both safflower-seed oil and fungal oil enhanced the splenic T-lymphoproliferative responses in healthy rats as determined ex vivo by a Con A proliferation assay, the responses being maximal after $4 \mathrm{~d}$ treatment with oils. In addition, safflower-seed-oil treatment at 4 and $12 \mathrm{~d}$ exerted a greater stimulatory effect on the Con $A$ response compared with fungal oil treatment. This may be due to a specific effect of linoleic acid or the higher administration dose. Importantly, these responses do not appear to be associated with significant changes in splenic $\mathrm{CD} 8^{+}$and $\mathrm{CD} 4^{+} \mathrm{T}$-cell sub-sets and also indicate that the oils do not produce gross $\mathrm{T}$-cell suppression. Effects of linoleic acid or linoleic-acid-rich oils on lymphocyte mitogenic responses appear to be inconsistent in the literature (Kelly \& Parker, 1979; Kollmorgen et al. 1979; Young et al. 1987; Calder et al. 1992). Important differences are, however, apparent when comparing results obtained in the present investigation with those of others. These differences include: the ex vivo nature of the present experiment rather than addition of fatty acids to cell culture medium; doses used; their routes of administration; species differences and the use of vitamin E-stripped oil by some workers. Moreover, the enhancement of the Con A response by both oils is an unexpected finding in view of the suppressive effects of the oils, at the same doses, on EAE, a T-cell mediated disease. It is possible, however, that the lympho-proliferative responses to neural-antigen(s) is specifically suppressed by the oils.

Biochemical evidence of increased proportions of membrane dihomo- $\gamma$-linolenic and arachidonic acids was observed in spleen phosphoglycerides effected by both oils, but particularly by fungal oil. This metabolic response in the case of fungal oil is most likely the result of its relatively high $\gamma$-linolenic acid content. The latter bypasses the rate-limiting $\Delta-6$ desaturase step and is converted to dihomo- $\gamma$-linolenic and arachidonic acids (Hassam et al. 1975; Phylactos et al. 1994). More importantly, fungal oil specifically decreased the spleen arachidonic : dihomo- $\gamma$-linolenic-acid ratio suggesting that the $\Delta-5$ desaturase is ratelimited in its ability to desaturate dihomo- $\gamma$-linolenic acid in fungal-oil-treated animals. It is therefore possible that dihomo- $\gamma$-linolenic acid may be responsible for fungal oil-induced suppression of EAE

The mechanism of action of the oils on EAE may be via modulation of critical Tlymphocyte surface molecules involved in antigen-specificity, self recognition, co-operative functions and/or T-cell receptor signal transduction. The precursor fatty acids dihomo- $\gamma-$ 
linolenic and arachidonic acids when converted to the eicosanoids prostaglandin $E_{1}\left(P_{1} E_{1}\right)$ and $\mathrm{PGE}_{2}$ respectively may also modify immune responses in $\mathrm{EAE}$. Effector T-lymphocytes in Lewis rat EAE are of the $\mathrm{CD} 4^{+} \mathrm{OX} 22^{+}$phenotype, a $\mathrm{CD} 4^{+}$sub-set known to produce high levels of interleukin-2 (IL-2) (Hayosh et al. 1989). The $\mathrm{CD}^{+} \mathrm{OX} 22^{+}$sub-set has lymphokine characteristics of mouse $\mathrm{CD}^{+}$clones designated $\mathrm{TH}_{1}$ (Mosmann \& Coffman, 1989). It is precisely this $\mathrm{CD}^{+}$sub-set that is $\mathrm{PGE}_{2}$-sensitive, $\mathrm{PGE}_{2}$ inhibiting both IL-2 and interferon- $\gamma$ (IFN- $\gamma$ ) production (Betz \& Fox, 1991). This could therefore be an immunoregulatory circuit whereby $\mathrm{PGE}_{2}$ or $\mathrm{PGE}_{1}$, both oxygenated $\mathrm{C} 20$-essential fatty acids, mediate the suppression of Lewis rat EAE. Cytokines other than these mentioned above, particularly transforming growth factor $\beta_{1}\left(\mathrm{TGF} \beta_{1}\right)$ and IL-4, may also be influenced by dihomo- $\gamma$-linolenic and arachidonic acids.

In summary, our studies show that Lewis rat EAE can be partially suppressed by linoleicacid-rich safflower-seed oil whilst $\gamma$-linolenic-acid-rich fungal oil, depending on dose, exerts full protection against the disease. In healthy Lewis rats oil doses found to be suppressive in EAE enhanced the splenic T-lymphoproliferative response to Con A, but did not affect the proportion of $\mathrm{CD}^{+}$or $\mathrm{CD} 4^{+}$cells. Biochemical studies suggest that with both oils these responses are associated with increased proportions of dihomo- $\gamma$-linolenic acid in spleen phospholipids, whilst fungal oil induces a specific increase in ethanolamine phosphoglyceride arachidonic acid and a decrease in the arachidonic:dihomo- $\gamma$-linolenic acid ratio in choline phosphoglycerides.

We wish to thank The Henry Smith Charity for generous financial support. Part of this work was carried out at the Nuffield Laboratories of Comparative Medicine, Institute of Zoology, The Zoological Society of London, Regents Park, London NW1 4RY under Home Office project licence no. 70/01381.

\section{REFERENCES}

Ackman, R. (1969). Gas liquid chromatography of fatty acids and esters. Methods in Enzymology 14, 329-381.

Alỵord, E. C., Kies, M. W. \& Suckling, A. J. (1984). Experimental Allergic Encephalomyelitis. A Useful Model for Multiple Sclerosis. New York: Alan R. Liss Inc.

Baker, R. W., Thompson, R. H. \& Zilkha, K. J. (1964). Serum fatty acids in multiple sclerosis. Journal of Neurology, Neurosurgery and Psychiatry 27, 408-414.

Bernard, C. A. A. \& Kerlere de Rorbo, N. K. (1992). Multiple sclerosis: an autoimmune disease of multifactorial aetiology. Current Opinion in Immunology 4, 760-765.

Betz, M. \& Fox, B.S. (1991). Prostaglandin $E_{2}$ inhibits production of $\mathrm{Th}_{1}$ lymphokines but not of $\mathrm{Th}_{2}$ lymphokines. Journal of Immunology 146, $108-113$.

Calder, P. C., Bevan, S. J. \& Newsholme, E. A. (1992). The inhibition of T-lymphocyte proliferation by fatty acids is via an eicosanoid-independent mechanism. Immunology 75, 108-115.

Cherayil, G. D. (1984). Sialic acid and fatty acid concentrations in lymphocytes, red blood cells, and plasma from patients with multiple sclerosis. Journal of the Neurological Sciences 63, 1-10.

Clarke, G. M. (1982). Statistics and Experimental Design. London: Edward Arnold Ltd.

Crawford, M. A., Rivers, J. P. \& Hassam, A. G. (1977). Comparative studies on the metabolic equivalence of linoleic and arachidonic acids. Nutrition and Metabolism 21, Suppl. 1, 189-190.

Cross, A. H., Cannella, B., Brosan, C. F. \& Raine, C. S. (1991). Hypothesis : antigen-specific T-cells prime central nervous system endothelium for recruitment of nonspecific inflammatory cells to effect autoimmune demyelination. Journal of Neuroimmunology 33, 237-244.

Dworkin, R. H., Bates, D., Millar, J. H. D. \& Paty, D. W. (1984). Linoleic acid and multiple sclerosis: a reanalysis of three double-blind trials. Neurology 34, 1441-1445.

Fallis, R. J., Powers, M. L. \& Weiner, H. L. (1987). Serial analysis of peripheral blood T-cell phenotypes and myelin basic protein reactivity in experimental allergic enceaphalomyelitis. Neurology 37, 719-723.

ffrench-Constant, C. (1994). Pathogenesis of multiple sclerosis. Lancet 343, 271-275.

Fisher, M., Johnson, M. H., Natale, A. M. \& Levine, P. H. (1987). Linoleic acid levels in white blood cells, platelets and serum of multiple sclerosis patients. Acta Neurologica Scandinavica 76, 241-245.

Folch, J., Lees, M. \& Sloane-Stanley, J. H. (1957). A simple method for the isolation and purification of total lipids from animal tissues. Journal of Biological Chemistry 226, 497-509. 
Harbige, L. S., Crawford, M. A., Jones, J., Preece, A. W. \& Fort, A. (1986). Dietary intervention studies on phosphoglyceride fatty acids and electrophoretic mobility of erythrocytes in multiple sclerosis. Progress in Lipid Research 25, 243-248.

Harbige, L. S., Ghebremeskel, K., Williams, G. \& Summers, P. (1990). N-3 and n-6 phosphoglyceride fatty acids in relation to in vitro erythrocyte haemolysis induced by hydrogen peroxide in captive common marmosets (Callithrix jacchus). Comparative Biochemistry and Physiology 97B, 167-170.

Hassam, A. G., Sinclair, A. J. \& Crawford, M. A. (1975). The incorporation of orally fed radioactive gammalinolenic acid and linoleic acid into the liver and brain lipids of suckling rats. Lipids 10, 417-420.

Hayosh, N. S., Karpus, W. J. \& Swanborg, R. H. (1989). Effector cells of autoimmune encephalomyelitis in the rat belong to the CD4-positive, OX22-adherent T-cell subset. Journal of Neuroimmunology 25, 57-61.

Hughes, D., Keith, A. B., Mertin, J. \& Caspary, E. A. (1980). Linoleic acid therapy in severe experimental allergic encephalomyelitis in the guinea pig. Clinical and Experimental Immunology 41, 523-531.

Kelly, J. P. \& Parker, C. W. (1979). Effects of arachidonic acid and other unsaturated fatty acids on mitogenesis in human lymphocytes. Journal of Immunology 122, 1556-1562.

Kollmorgen, G. M., Sansing, W. A., Lehman, A. A., Fischer, G., Longley, R. E., Alexander, S. S., King, M. M. \& McCay, P. B. (1979). Inhibition of lymphocyte function in rats fed high-fat diets. Cancer Research 39, 3458-3462.

Lassmann, H. (1983). Comparative Neuropathology of Chronic Experimental Allergic Encephalomyelitis and Multiple Sclerosis. Berlin: Springer-Verlag.

Meade, C. J., Mertin, J., Sheena, J. \& Hunt, R. (1978). Reduction by linoleic acid of the severity of experimental allergic encephalomyelitis in the guinea pig. Journal of the Neurological Sciences 35, 291-308.

Mertin, J. (1981). Essential fatty acids and cell-mediated immunity. Progress in Lipid Research 20, 851-856.

Mertin, J. \& Stackpoole, A. (1978). Suppression by essential fatty acids of experimental allergic encephalomyelitis is abolished by indomethacin. Prostaglandins and Medicine 1, 283-291.

Mertin, J. \& Stackpoole, A. (1979). The spleen is required for the suppression of experimental allergic encephalomyelitis by prostaglandin precursors. Clinical and Experimental Immunology 36, 449-455.

Mertin, J., Stackpoole, A. \& Shumway, S. J. (1984). Prostaglandins and cell-mediated immunity. Transplantation 37, 396-402.

Mertin, J., Stackpoole, A. \& Shumway, S. J. (1985). Nutrition and immunity: the immunoregulatory effect of n-6 essential fatty acids is mediated through prostaglandin-E. International Archives of Allergy and Applied Immunology 77, 390-395.

Mosmann, T. R. \& Coffman, R. L. (1989). Th1 and Th2 cells: different patterns of lymphokine secretion lead to different functional properties. Annual Review of Immunology 7, 145-173.

Navarro, X. \& Segura, R. (1989). Red blood cell fatty acids in multiple sclerosis. Acta Neurologica Scandinavica 79, 32-37.

Neu, I. S. (1983). Essential fatty acids in the serum and cerebrospinal fluid of multiple sclerosis patients. Acta Neurological Scandinavica 67, 151-163.

Paterson, P. Y. (1980). The immunopathology of experimental allergic encephalomyelitis. In The Suppression of Experimental Allergic Encephalomyelitis and Multiple Sclerosis, pp. 11-29 [A. N. Davison and M. L. Cuzner, editors]. London: Academic Press Inc.

Phylactos, A. C., Harbige, L. S. \& Crawford, M. A. (1994). Essential fatty acids alter the activity of manganesesuperoxide dismutase in rat heart. Lipids 29, 111-115.

Sanders, H., Thompson, R. H., Wright, H. P. \& Zilkha, K. J. (1968). Further studies on platelet adhesiveness and serum cholesteryl linoleate levels in multiple sclerosis. Journal of Neurology, Neurosurgery and Psychiatry 31 , 321-325.

Stackpoole, A. \& Mertin, J. (1981). The effect of prostaglandin precursors in in vivo models of cell-mediated immunity. Progress in Lipid Research 20, 649-654.

Tsang, W. M., Berlin, J., Monro, J. A., Smith, A. D., Thompson, R. H. S. \& Zilkha, K. J. (1976). Relationship between plasma and lymphocyte linoleate in multiple sclerosis. Journal of Neurology, Neurosurgery and Psychiatry 39, 767-771.

Young, M. R., Ellis, N. K., Young, M. E. \& Wepsic, H. T. (1987). Stimulation of hematopoiesis and bone marrow suppressor cells by subcutaneous injection of linoleic acid. Cellular Immunology 107, 238-248. 